\title{
Short-Term Tolerance of Nasally-Administered NeuroEPO in Patients with Parkinson Disease
}

\author{
Marité García-Llano MD MS, Ivonne Pedroso-lbáñez MD MS, Lilia Morales-Chacón MD PhD DSc, Teresita Rodríguez-Obaya MD PhD, \\ Leslie Pérez-Ruiz MS, Iliana Sosa-Testé DVM PhD, Daniel Amaro González PhD, María Luisa Bringas-Vega PhD
}

\begin{abstract}
INTRODUCTION No neuroprotective treatment has been able to successfully halt the progression of Parkinson disease or prevent development of associated complications. Recombinant erythropoetin (EPO), an erythropoiesis-stimulating agent originally indicated in anemia, produced and manufactured in Cuba (iorEPOCIM, CIMAB S.A, Havana, Cuba) has neuroprotective properties. NeuroEPO is a new nasal formulation of recombinant EPO with a low content of sialic acid and without hematopoietic effects. It has neuroprotective effects in animal models.
\end{abstract}

OBJECTIVE Evaluate short-term tolerance of intranasal NeuroEPO in patients with Parkinson disease.

METHODS As part of a monocentric randomized placebo-controlled double-blind study (registered at www.clinicaltrials.gov number NCT04110678), 26 patients with Parkinson disease (stages 1 and 2 on Hoehn \& Yahr Scale), were randomly divided into two groups: NeuroEPO $(n=15)$ and placebo $(n=11)$, both treated intranasally either with the drug ( $1 \mathrm{~mL}$, at a concentration of $1 \mathrm{mg} / \mathrm{mL}$ of NeuroEPO) or

\section{INTRODUCTION}

Parkinson disease (PD) is the second leading neurodegenerative disorder in the world after Alzheimer disease.[1] Disability caused by $P D$ is a growing economic and social burden that parallels the aging of the world's population.[2] PD is characterized by progressive loss of dopaminergic neurons. Dopamine precursors (such as L-3,4-dihydroxyphenylalanine, L-DOPA) are the first line of therapy, but only provide a symptomatic remedy since they do not modify the course of the disease. For this reason, one of the main lines of investigation worldwide is the search for neuroprotective agents.[3,4]

There is evidence that erythropoietin (EPO), an erythropoiesisstimulating agent important in tissue oxygenation, with roles originally indicated in anemia and kidney failure, has neuroprotective properties.[5,6] EPO has a demonstrated effect on mechanisms involved in cell death due to its antiapoptotic and antioxidant qualities, which prevent cell damage during the nitric oxide cascade. These qualities also lend themselves to EPO's neurotrophic effects and its effects on neurogenesis. It is believed that EPO protects neurons through a combination of these mechanisms. $[7,8]$ EPO modulates neuroinflammation through neurotrophic

\section{IMPORTANCE}

This article shows that NeuroEPO is safe and well tolerated by patients with Parkinson disease and proposes recommendations for the use of this compound as a neuroprotector. placebo once a week for 5 weeks. At each application, we recorded any adverse events and blood pressure. To assess potential hematopoietic effects of the drug, hematological and biochemical variables were evaluated one week before and one week after the intervention.

RESULTS There were no significant differences ( $p=0.22$ ) between the two groups in terms of frequency of adverse events $(20.0 \%$ in NeuroEPO and $9.1 \%$ in placebo groups). Three patients in NeuroEPO presented nausea, and one vomited (possibly due to the patient's positioning during drug application). One patient in placebo group reported polyuria and nasal irritation. In both groups, the adverse events were mild, brief, required no treatment and did not present sequelae.

CONCLUSION Nasally administered NeuroEPO for five weeks in patients with Parkinson disease stages 1 and 2 on Hoehn \& Yahr Scale is well tolerated.

KEYWORDS Parkinson disease, intranasal drug, neurodegenerative diseases, erythropoietin, biopharmaceutics, Cuba

actions on astrocytes, microglia and neurons.[9] It can pass through the blood-brain barrier and acts on the central nervous system through inhibition of apoptosis in microvascular endothelial cells and activation of astrocytes.[10,11]

EPO has a high content of sialic acid, which protects it from hepatic degradation and enables its erythropoietic function, causing a rise in hemoglobin synthesis and blood pressure.[12] These effects are not present in NeuroEPO due to its low content of sialic acid. The molecule thus conserves its neuroprotective properties without its hematopoietic activity, which makes it a better candidate as a neuroprotective agent.[10,11]

NeuroEPO is produced by the Molecular Immunology Center (CIM, CIMAB S.A., Havana, Cuba) and is under study at the Center for Drug Research and Development (CIDEM, Havana, Cuba.)

The safety and tolerance of NeuroEPO have been proven in healthy people[13] (Cuban Public Registry of Clinical Trials RPCEC00000157) but there is no evidence yet of PD patients' tolerance of the drug.

This study evaluates short-term tolerance of intranasally administered NeuroEPO in patients with PD stages 1 and 2 on the Hoehn and Yahr Scale.[14] It examines the onset of adverse events and their potential effect on blood pressure and hematological variables.

\section{METHODS}

A monocentric randomized placebo-controlled double-blind clinical trial (registered at www.clinicaltrials.gov number NCT04110678) was conducted to evaluate tolerance and safety of NeuroEPO in PD patients. 
Participants Participants were recruited from February 1, 2015 through July 31, 2015 at the outpatient services at the Movement Disorder Clinic, International Neurological Restoration Center (CIREN) in Havana, Cuba, 46 of whom were diagnosed with idiopathic Parkinson disease in accordance with the operational criteria of the Brain Bank of London (BBL).[15]

Inclusion criteria A prior EPO-tolerance study by our group[16] using ior EPOCIM provided the framework for inclusion criteria:

- at least one year since PD onset, so disease progression can confirm diagnosis

- no limit on number of years since disease onset of PD whenever patient's severity is between stages 1 and 2 on the Hoehn \& Yahr (H\&Y) Scale[14]

- age 40-70 years

- good response to dopaminergic stimulation with $>30 \%$ change in score on the motor section of the Movement Disorders SocietyUnified Parkinson Disease Rating Scale (MDS-UPDRS)[17]

- no cognitive decline (>26 points) as measured by the MiniMental State Examination (MMSE).[18]

Exclusion criteria Because EPO stimulates erythrocyte formation and is a leading natural erythropoiesis-stimulating agent, the following individuals should be excluded from its use and were excluded from the study: pregnant and breastfeeding women; women of childbearing age who use contraceptives; patients with hematological disorders (sickle cell disease, myelodysplastic syndromes, active clotting and bleeding disorders), peripheral vascular diseases, renal or hepatic insufficiency, polycythemia, or hematocrit $\geq 50$. Due to the intranasal administration, patients with allergic rhinitis or vasomotor rhinitis in its acute phase were excluded, as well as those with nasal cavity malformations. We also excluded patients with sepsis or active acute or chronic inflammatory diseases; malignant tumors or cancer treatment; alcoholism or drug addiction in the two years prior to the study; high blood pressure or other decompensated chronic illnesses; or patients receiving immunosuppressant, androgen or anabolic steroid treatments in the month prior to recruitment.

The sample size was selected following the established international practice for tolerance clinical trials that emphasize the need to minimize the number of subjects exposed to an experimental product.[19,20]

In order to assign patients to the groups, the Molecular Immunology Center (CIM, provider of the drug) automatically generated a single list of randomized numbers and labeled the vials containing the product and cases with the corresponding code. Although the initial study design called for only 20 patients, the decision was made to include more patients due to the satisfactory tolerance results obtained in a clinical trial on healthy subjects and subjects with ataxia.[13] The same coding method was applied until completion of the final sample $(n=26)$, made up of 15 patients treated with NeuroEPO and 11 patients treated with placebo.

Criteria for removal from the study Accidents or another disease diagnosed during the study that would exclude a participant; patient's expressed interest in abandoning the study; treatment suspended for more than one dose, consecutively or in isolated instances; and death.
Product and administration NeuroEPO is presented in a singledose $1-\mathrm{mL}$ vial, containing $1 \mathrm{mg} / \mathrm{mL}$ of low sialic acid, recombinant human erythropoietin (rHu-EPO) produced in cultures of the ovarian cells of Chinese hamsters ( $\mathrm{CHO}$ cells). Each vial also contains polysorbate 80 , sodium edetic acid, sodium chloride, medium molecular weight hydroxypropyl methylcellulose thickener and water for injection. The placebo formula is identical except for absence of the active ingredient. The drug was administered intranasally once a week for five consecutive weeks with the patient lying in a supine position. During the first application, the patient's head was inclined at a 45-degree angle below the horizontal plane of the body, to ensure that the product arrives to its site of action. A dose of $0.5 \mathrm{~mL}$ was administered slowly in each nostril as two doses of $0.25 \mathrm{~mL} 15$ minutes apart. This ensured arrival at the superior turbinate while keeping in mind the maximum capacity for intranasal medications.[21,22] The initial maximum dose was based on preclinical and clinical studies, as well as safety guidelines.[23-28]

Hematological and biochemical tests Blood tests were conducted prior to start of treatment and one week after completion. These included: hemoglobin, hematocrit, platelet count and erythrocyte-sedimentation rate, creatinine, uric acid, glutamic oxaloacetic transaminase, glutamic pyruvic transaminase, gamma-glutamyl transpeptidase, cholesterol and triglycerides. For statistical analysis, calculations were made of the relative change in all hematological and biochemical parameters, defined as the difference between the two measurements divided by the initial value.

Clinical evaluation Vital signs were measured before treatment and one hour after drug application. Tolerance was evaluated during the entire study through investigation of adverse events via patient surveys after each treatment session. In the case of an adverse event, the medical researcher acted in accordance with its nature and severity.

Definition and classification of adverse events An adverse event was considered as any unfavorable medical event presenting in patients receiving the product without necessarily having a causal relation with treatment. Adverse events were classified as local (site of application) or systemic,[29] in accordance with guidelines provided by the Center for State Control of Medicines and Medical Devices (CECMED). An event was considered mild if it was well tolerated, caused minimum bother, and did not interfere with daily activities; moderate if it was a bother but did not interfere with daily activities; and severe if it did interfere with daily activities.[30] The causal relation was classified as: "Extremely likely/sure," "Likely," "Possible," "Unlikely," "Not related," or "Not able to be evaluated/unclassifiable," according to WHO causality criteria.[31] The participants' code was opened after study completion, which enabled identification of patients belonging to each group.

Ethical considerations The study adhered to the ethical considerations of the Declaration of Helsinki.[32] Written informed consent was obtained from all participants; and confidentiality was ensured.

Statistical procedures Information was summarized in means and standard deviations for quantitative data and in percentages for qualitative data. To compare distribution of frequencies of the 
two groups' adverse events, the Chi square $\left(\mathrm{X}^{2}\right)$ test was used. For comparisons of the groups with respect to the continuous variables, two analytically equivalent procedures were used: (a) an analysis of variance for repeated observations in the readings of systolic and diastolic blood pressure (taking the pretreatment value as a covariant); and (b) for all other variables, comparison of means for independent groups based on relative change.

\section{RESULTS}

Participants' demographic and clinical characteristics were collected during enrollment (Table 1). All participants remained in the study through its completion.

Adverse events occurred in both groups: four adverse events in three patients in the NeuroEPO group $(20.0 \%)$ and two adverse events in one patient in the placebo group $(9.1 \%)$, with no significant differences between groups $(p=0.22)$ (Table 2$)$. All events were mild and likely related to the patient's positioning during product administration. One patient in the placebo group presented polyuria and nasal irritation in the second application, apparently unrelated to the product, as this effect was not reported

Table 1: Demographic and clinical characteristics of the NeuroEPO group and placebo group

\begin{tabular}{|c|c|c|c|}
\hline Parameter & NeuroEPO & Placebo & Total \\
\hline \multicolumn{4}{|l|}{ Age } \\
\hline Mean (SD) & $56.4(7.8)$ & $61.1(6.6)$ & $58.4(7.6)$ \\
\hline \multicolumn{4}{|l|}{ Sex } \\
\hline Male & $7(46.6 \%)$ & $8(72.7 \%)$ & $15(55 \%)$ \\
\hline Female & $8(53.4 \%)$ & $3(27.2 \%)$ & $11(45 \%)$ \\
\hline \multicolumn{4}{|l|}{ H\&Y Scale } \\
\hline 1 & $4(26.6 \%)$ & $1(9.1 \%)$ & $5(19.2 \%)$ \\
\hline 2 & $11(73.4 \%)$ & $10(90.9 \%)$ & $21(80.8 \%)$ \\
\hline \multicolumn{4}{|c|}{ PD Progression (years post-diagnosis) } \\
\hline & $5.4(3.2)$ & $5.8(4.1)$ & $5.6(3.5)$ \\
\hline \multicolumn{4}{|c|}{ PD in family history } \\
\hline Yes & $6(40 \%)$ & $3(27.2 \%)$ & $9(34.6 \%)$ \\
\hline No & $9(60 \%)$ & $8(72.8 \%)$ & $17(65.4 \%)$ \\
\hline \multicolumn{4}{|c|}{ Personal history of other chronic disorders } \\
\hline Yes & $8(53.4 \%)$ & $7(63.6 \%)$ & $15(57.7 \%)$ \\
\hline No & $7(46.6 \%)$ & $4(36.4 \%)$ & $11(42.3 \%)$ \\
\hline \multicolumn{4}{|c|}{ Use of levodopa } \\
\hline Yes & $11(73.3 \%)$ & $9(81.8 \%)$ & $20(76.9 \%)$ \\
\hline No & $4(26.7 \%)$ & $2(18.2 \%)$ & $6(23.1 \%)$ \\
\hline \multicolumn{4}{|c|}{ Use of precursors } \\
\hline Yes & $9(60 \%)$ & $6(54.5 \%)$ & $15(57.7 \%)$ \\
\hline No & $6(40 \%)$ & $5(45.5 \%)$ & $11(42.3 \%)$ \\
\hline \multicolumn{4}{|c|}{ Use of neuroprotectors } \\
\hline Yes & $1(6.7 \%)$ & $2(18.2 \%)$ & $3(11.5 \%)$ \\
\hline No & $14(93.3 \%)$ & $9(81.8 \%)$ & $23(88.5 \%)$ \\
\hline \multicolumn{4}{|c|}{ Use of other drugs } \\
\hline Yes & $8(53.3 \%)$ & $5(45.4 \%)$ & $13(50 \%)$ \\
\hline No & $7(46.7 \%)$ & $6(54.6 \%)$ & $13(50 \%)$ \\
\hline
\end{tabular}

H\&Y Scale: disease severity according to Hoehn \& Yahr Scale;[14] PD: Parkinson disease; Precursors: dopaminergic drug precursors; neuroprotectors: drugs with proven neuroprotective action; other drugs: those used for PD patients' comorbidities (anti-hypertensives, lipid-lowering, etc.)
Table 2: Description and follow-up for adverse events upon NeuroEPO or placebo application

\begin{tabular}{|c|c|c|c|c|}
\hline \multirow[b]{2}{*}{ Parameter } & \multicolumn{4}{|c|}{ Participant } \\
\hline & $\begin{array}{c}\text { JDA-02 } \\
\text { (placebo) }\end{array}$ & $\begin{array}{c}\text { MRLL-06 } \\
\text { (NeuroEPO) }\end{array}$ & $\begin{array}{c}\text { LAPG-12 } \\
\text { (NeuroEPO) }\end{array}$ & $\begin{array}{c}\text { NAR-09 } \\
\text { (NeuroEPO) }\end{array}$ \\
\hline Adverse events & 2 & 2 & 1 & 1 \\
\hline Nausea & & 1 & 1 & 1 \\
\hline Vomiting & & 1 & & \\
\hline Nasal itching & 1 & & & \\
\hline Polyuria & 1 & & & \\
\hline Onset & $\begin{array}{r}2 \mathrm{nd} \\
\text { application }\end{array}$ & $\begin{array}{r}1 \mathrm{st} \\
\text { application }\end{array}$ & $\begin{array}{r}1 \mathrm{st} \\
\text { application }\end{array}$ & $\begin{array}{r}1 \mathrm{st} \\
\text { application }\end{array}$ \\
\hline Duration & 4 hours & 3 hours & 2 hours & 10 hours \\
\hline Intensity* & Mild & Mild & Mild & Mild \\
\hline Causality & Not related & $\begin{array}{r}\text { Extremely likely/ } \\
\text { sure }\end{array}$ & $\begin{array}{r}\text { Extremely likely/ } \\
\text { sure }\end{array}$ & $\begin{array}{r}\text { Extremely likely/ } \\
\text { sure }\end{array}$ \\
\hline Outcome & Recovery & Recovery & Recovery & Recovery \\
\hline Conduct & Observation & Observation & Observation & Observation \\
\hline
\end{tabular}

* Intensity of event was classified based on CDER guidelines.[27] Mild corresponds to Grade 1 in the Common Terminology Criteria for Adverse Events (CTCAE, https://www.uptodate.com/ contents/common-terminology-criteria-for-adverse-events)

Table 3: Blood pressure for both groups pretreatment, during study and post-treatment

\begin{tabular}{l|r|r|}
\hline Parameter & \multicolumn{2}{|c}{ Group } \\
\hline Blood pressure & NeuroEPO & \multicolumn{1}{|c|}{ Placebo } \\
\hline Pre-SBP & $125.6(9.4)$ & $129(9.2)$ \\
\hline Pre-DBP & $79.3(7.0)$ & $79.1(4.9)$ \\
\hline SBP 1 & $122.3(10.4)$ & $126.3(14.8)$ \\
\hline DBP 1 & $77(5.9)$ & $79.5(9.1)$ \\
\hline SBP 2 & $121(8.4)$ & $121.3(10.0)$ \\
\hline DBP 2 & $79(5.9)$ & $77.7(6.1)$ \\
\hline SBP 3 & $121(8.4)$ & $125.9(11.3)$ \\
\hline DBP 3 & $74(7.1)$ & $78.3(6.7)$ \\
SBP 4 & $122.6(15.1)$ & $126.8(9.5)$ \\
\hline DBP 4 & $70(4.4)$ & $80.4(5.6)$ \\
SBP 5 & $120.3(8.1)$ & $123.6(8.9)$ \\
DBP 5 & $70(4.4)$ & $78.6(5.5)$ \\
Post-SBP & $122.3(8.4)$ & $124.1(10.4)$ \\
Post-DBP & $70(3.2)$ & $78.1(2.5)$ \\
Fa $=0.27(p=0.90)$ & &
\end{tabular}

SBP: systolic blood pressure ( $\mathrm{mmHg})$; DBP: diastolic blood pressure $(\mathrm{mmHg})$; pre: pre-treatment; post: post-treatment (one week after final application of product). Numbers correspond to week of treatment. Figures correspond to means and standard deviations (in parentheses). a: Fisher's overall test for the effect of change in a repeated observations analysis of variance.

for recombinant EPO or in the NeuroEPO tolerance study involving healthy subjects.[13] Three patients in the NeuroEPO group presented systemic events: immediate nausea on first administration and in one case, vomiting. Event duration was three to ten hours, with a steady decline in symptom intensity over time. All events required only observation, and patients experiencing the adverse event spontaneously recovered without sequelae or need for medication.

Blood pressure readings were within normal range for participants in both groups, both before application of the product and in the five post-application measurements (Table 3 ). The hematological and biochemical parameters remained steady and with- 
Table 4: Relative change in hematological parameters pre- and posttreatment in the NeuroEPO and placebo groups

\begin{tabular}{|c|c|c|c|c|}
\hline \multirow{2}{*}{ Parameter } & \multicolumn{2}{|c|}{ Group } & \multirow{2}{*}{$t^{a}$} & \multirow{2}{*}{$p^{b}$} \\
\hline & NeuroEPO & Placebo & & \\
\hline Pre-hemoglobin & $13.1(1.4)$ & $13.6(1.4)$ & \multirow{2}{*}{0.36} & \multirow{2}{*}{0.72} \\
\hline Post-hemoglobin & $13.1(1.2)$ & $13.7(1.4)$ & & \\
\hline Pre-hematocrit & $41.6(3.8)$ & $41.6(3.2)$ & \multirow{2}{*}{0.47} & \multirow{2}{*}{0.64} \\
\hline Post-hematocrit & $43.3(4.9)$ & $41.6(3.2)$ & & \\
\hline $\begin{array}{l}\text { Pre-erythrocyte } \\
\text { sedimentation rate }\end{array}$ & $8.6(5.8)$ & $9.8(9.4)$ & \multirow{2}{*}{0.73} & \multirow{2}{*}{0.47} \\
\hline $\begin{array}{l}\text { Post-erythrocyte } \\
\text { sedimentation rate }\end{array}$ & $8.0(6.9)$ & $9.2(8.7)$ & & \\
\hline Pre-platelet & $242.4(51.3)$ & $236.6(57.4)$ & \multirow{2}{*}{0.29} & \multirow{2}{*}{0.77} \\
\hline Post-platelet & $236.1(50.6)$ & $226.2(56.5)$ & & \\
\hline
\end{tabular}

Pre: pre-treatment; Post: Post-treatment (1 week after final application of product). Data presented as means and standard deviations in parentheses.

a: Value of comparison t-Student test (means over relative change) in the groups.

b: $p$ value associated with comparison test.

Table 5: Relative changes of pre-and post-treatment biochemical parameters in the NeuroEPO and placebo groups

\begin{tabular}{|c|c|c|c|c|}
\hline Parameter & NeuroEPO & Placebo & $\mathbf{t}^{\mathbf{a}}$ & $\mathbf{p}^{b}$ \\
\hline Pre-creatinine $(\mu \mathrm{mol} / \mathrm{L})$ & $89.9(25.3)$ & $90.6(11.6)$ & \multirow{2}{*}{1.71} & \multirow{2}{*}{0.10} \\
\hline Post-creatinine $(\mu \mathrm{mol} / \mathrm{L})$ & $95.7(13.8)$ & $88.7(15.2)$ & & \\
\hline Pre-uric acid $(\mu \mathrm{mol} / \mathrm{L})$ & $288.8(77.0)$ & $291.3(68.7)$ & \multirow{2}{*}{1.57} & \multirow{2}{*}{0.13} \\
\hline Post-uric acid ( $\mu \mathrm{mol} / \mathrm{L})$ & $294.3(58.9)$ & $279.4(88.6)$ & & \\
\hline Pre-GPT (u/L) & $22.1(6.2)$ & $16.7(10.6)$ & \multirow{2}{*}{0.71} & \multirow{2}{*}{$0.4 \varepsilon$} \\
\hline Post-GPT (u/L) & $15.6(9.0)$ & $17.4(6.14)$ & & \\
\hline Pre-GOT (u/L) & $22.1(6.2)$ & $27.2(17.8)$ & \multirow{2}{*}{0.59} & \multirow{2}{*}{0.56} \\
\hline Post-GOT (u/L) & $20.2(5.2)$ & $20.1(4.02)$ & & \\
\hline Pre-GGT (u/L) & $28(24.9)$ & $37.6(33.7)$ & \multirow{2}{*}{0.67} & \multirow{2}{*}{0.51} \\
\hline Post-GGT (u/L) & $23.2(13.1)$ & $30(25.5)$ & & \\
\hline Pre-TGC (mmol/L) & $0.9(0.5)$ & $1.0(0.6)$ & \multirow{2}{*}{0.54} & \multirow{2}{*}{0.59} \\
\hline Post-TGC (mmol/L) & $0.9(0.4)$ & $0.9(0.5)$ & & \\
\hline Pre-cholesterol (mmol/L) & $4.5(1.0)$ & $4.9(0.9)$ & \multirow{2}{*}{1.14} & \multirow{2}{*}{0.27} \\
\hline Post-cholesterol (mmol/L) & $4.5(0.9)$ & $4.6(1.0)$ & & \\
\hline
\end{tabular}

Legend: GPT: glutamic pyruvic transaminase; GOT: glutamic oxaloacetic transaminase; GGT: gamma-glutamyl transpeptidase, TGC: Triglycerides; Pre: day zero, pre-treatment, Post: post- treatment (1 week after final application of product). Data presented as means and standard deviations in parentheses.

a: $t$-Student comparison test (means over relative change) in the groups.

b: $p$ value associated with comparison test.

in normal limits (Tables 4 and 5), and for this reason statistical tests (intra- and inter-group) were not performed. The means of each parameter for each group were similar before treatment and one week after treatment completion (Tables 3-5).

\section{DISCUSSION}

This clinical trial confirms PD patients' short-term tolerance to intranasally administered NeuroEPO at the doses employed. There is an imbalance in sex and severity in both groups. In our opinion, this disparity did not influence the results of the trial.

Sex The prevalence of PD is lower in females than in males, in a proportion 1:3.[32,33] In our study, the placebo group had fewer women $(n=3)$ than the NeuroEPO group $(n=8)$. This is an effect of general randomization; it does not have the same implication as in a drug-efficacy study. Due to its angiogenic effect, EPO could act in females as a hormone, playing a role in reproductive organ function; $[34,45]$ this effect is not present in NeuroEPO, a form of EPO without the hematopoietic effect. In addition, women of childbearing age/pregnant women were excluded in the recruitment process.

Severity PD severity was evaluated using the H\&Y scale. The placebo group had only one patient in $\mathrm{H} \& Y$ stage 1 , while the NeuroEPO group had four. This imbalance was present in recruited participants (only 10 of the 46 patients who met the $\mathrm{BBL}$ criteria were in $\mathrm{H} \& Y$ stage 1 while 36 were in $\mathrm{H} \& Y$ stage 2 ). In our experience the symptoms of stage-1 patients are mild and patients rarely seek treatment, while stage-2 patients present bilateral motor compromise so they often volunteer to participate in clinical trials.

Tolerance We did not find significant changes in the hematological parameters. Four adverse events occurred in three patients treated with NeuroEPO (20\%); all were mild and happened after the first intranasal administration. The frequency of adverse events reported here is lower than that found in the NeuroEPO clinical trial conducted in healthy individuals,[13] where $80 \%$ of the subjects who received NeuroEPO reported at least 1 mild adverse event. This can be related to the lower doses and frequency employed in our study $(1 \mathrm{mg}$, once per week for five weeks), where for the first time, patients with Parkinson were exposed to this molecule, in comparison with $1 \mathrm{mg}$ every eight hours for four days.[13]

Evidence showed good local tolerance. The mild adverse events at site of administration are similar to those observed in preclinical studies with both NeuroEPO and controls in the nasal irritation test and could be considered to be common when using this route of administration.[23]

The nausea reported by three patients in the NeuroEPO group was not reported in the study with healthy volunteers. This adverse event could be explained by the positioning of the patient's head for half an hour during the administration of the drug (lowered at an angle to the body). These events occurred in the first administration. In subsequent applications of the drug, head position was modified, adopting a horizontal position, and this effect disappeared.

The data indicate an appropriate dose level at which NeuroE$P O$ can be safely nasally administered to PD patients. A phase 2-3 clinical trial of NeuroEPO is now underway to evaluate its possible beneficial effects.

\section{CONCLUSIONS}

Nasal administration of NeuroEPO in patients with Parkinson disease (stages 1 and 2 on the Hoehn \& Yahr Scale) is well tolerated. These results endorse further clinical study of this product for PD treatment.

\section{ACKNOWLEDGMENTS}

We thank the patients and their providers who volunteered to participate in this clinical trial, as well as all those who cooperated with the study: nurses, physicians, laboratory technicians and employees of CIREN, and the CIM specialists who provided the product and methodology used in the study. -1 - 


\section{REFERENCES}

1. Leverenz JB, Quinn JF, Zabetian C, Zhang J, Montine K, Montine T. Cognitive impairment and dementia in patients with Parkinson disease. Curr Top Med Chem. 2009;9(10):903-12.

2. GBD 2016 Parkinson's Disease Collaborators. Global, regional, and national burden of Parkinson's disease, 1990-2016: a systematic analysis for the Global Burden of Disease Study 2016. Lancet Neurol. 2018 Nov 1;17(11):93953.

3. Braak H, Del Tredici K, Rüb U, de Vos RA, Jansen Steur ENH, Braak E. Staging of brain pathology related to sporadic Parkinson's disease. Neurobiol Aging. 2003 Mar-Apr;24(2):197-211.

4. Nutt JG, Wooten GF. Clinical practice. Diagnosis and initial management of Parkinson's disease. N Engl J Med. 2005 Sep 8;353(10):1021-7.

5. Toba H, Kojima Y, Wang J, Noda K, Tian W, Kobara $M$, et al. Erythropoietin attenuated vascular dysfunction and inflammation by inhibiting NADPH oxidase-derived superoxide production in nitric oxide synthase-inhibited hypertensive rat aorta. Eur J Pharmacol. 2012 Sep;691(1-3):190-7.

6. Ge XH, Zhu GJ, Geng DQ, Zhang ZJ, Liu CF. Erythropoietin attenuates 6-hydroxydopamineinduced apoptosis via glycogen synthase kinase 3beta-mediated mitochondrial translocation of Bax in PC12 cells. Neurol Sci. 2012 Dec;33(6):1249-56.

7. Liu P, Liu X, Liou AK, Xing J, Jing Z, Ji X, et al. The neuroprotective mechanism of erythropoietinTAT fusion protein against neurodegeneration from ischemic brain injury. CNS Neurol Disord Drug Targets. 2014;13(8):1465-74.

8. Ugurluer G, Cebi A, Mert H, Mert N, Serin M, Erkal HS. Neuroprotective effects of erythropoietin against oxidant injury following brain irradiation: an experimental study. Arch Med Sci. 2016 Dec 1;12(6):1348-53.

9. Bond WS, Rex TS. Evidence that erythropoietin modulates neuroinflammation through differential action on neurons, astrocytes, and microglia. Front Immunol. 2014 Oct 24;5:523.

10. Maiese K, Chong ZZ, Shang YC, Wang S. Erythropoietin: new directions for the nervous system. Int J Mol Sci. 2012;13(9):11102-29.

11. Erbas $O$, Cinar BP, Solmaz V, Çavuşoğlu T, Ates $U$. The neuroprotective effect of erythropoietin on experimental Parkinson model in rats. Neuropeptides. 2015 Feb;49:1-5.

12. FARMACODIVULGACION: Eritropoyetina humana recombinante. Rev Cubana Farm. 2012 AprJun;46(2):287-8. Spanish.

13. Santos-Morales O, Díaz-Machado A, JiménezRodríguez D, Pomares-Iturralde Y, FesteryCasanovas T, González-Delgado CA, et al. Nasal administration of the neuroprotective candidate NeuroEPO to healthy volunteers: a randomized, parallel, open level safety study. BMC Neurol. 2017 Jul 4;17(1):129.

14. Hoehn MM \& Yahr MD. Parkinsonism: onset, progression and mortality. Neurology. 1967;17:427-27.

15. Hughes AJ, Daniel SE, Kilford L, Lees AJ. Accuracy of clinical diagnosis of idiopathic Parkinson's disease: a clinico-pathological study of 100 cases. J Neurol Neurosurg Psychiatry.1992 Mar;55(3):181-4.

16. Pedroso I, Bringas ML, Aguiar A, Morales L, Álvarez M, Valdés PA. Use of Cuban recombinant human erythropoietin in Parkinson's disease treatment. MEDICC Rev. 2012 Jan;14(1):11-7.

17. Goetz CG, Tilley BC, Shaftman SR, Stebbins GT, Fahn S, Martínez-Martín P, et al. Movement Disorder Society-sponsored revision of the Unified Parkinson's Disease Rating Scale (MDSUPDRS): scale presentation and clinometric testing results. Move Disord. 2008 Nov 15;23(15):2129-70.

18. Folstein $M$, Robins $N$, Helzer, J. The minimental state examination. Arch Gen Psychiatry. 1983;40:812.

19. Buoen C, Bjerrum OJ, Thomsen MS. How firsttime-in-human studies are being performed: a survey of phase I dose-escalation trials in healthy volunteers published between 1995 and 2004. J Clin Pharmacol. 2005 Oct;45(10):1123-36.

20. European Medicines Agency. Committee for Medicinal Products for Human Use (CHMP). Guideline on strategies to identify and mitigate risks for first-in-human and early clinical trials with investigational medicinal products. Draft [Internet]. London: European Medicines Agency Committee for Medicinal Products for Human Use (CHMP); 2016 Nov 15 [cited 2020 May 5]. 22 p. Available at: https://www.ema.europa .eu/en/documents/scientific-guideline/draft -guideline-strategies-identify-mitigate-risks-first -human-early-clinical-trials-investigational_en.pdf

21. Dhuria SV, Hanson LR, Frey WH 2nd. Intranasal delivery to the central nervous system: mechanisms and experimental considerations. J Pharm Sci. 2010 Apr;99(4):1654-73.

22. Muñoz-Cernada $A$, Fernández-Cervera $M$, García-Rodríguez JC. Factors involved in the design of nasal delivery systems for peptides and proteins. Biotecnol Apl. 2013;30(2):88-96.

23. Sosa Testé I, García Rodríguez JC, García JD, Santana J, Subirós N, González C. Intranasal administration of recombinant human erythropoietin exerts neuroprotective effects on post-ischemic brain injury in Mongolian gerbils. Pharmacol Online. 2006;1:100-12.

24. Lagarto A, Bueno V, Guerra I, Valdés O, Couret $M$, López R, et al. Absence of hematological side effects in acute and subacute nasal dosing of erythropoietin with a low content of sialic acid. Exp Toxicol Pathol. 2011 Sep;63(6):563-7.

25. Ehrenreich $\mathrm{H}$, Hasselblatt $\mathrm{M}$, Dembowski C, Cepek L, Lewczuk P, Stiefel M, et al. Erythropoietin therapy for acute stroke is both safe and beneficial. Mol Med. 2002 Aug; 8(8):495-505.

26. Ehrenreich $\mathrm{H}$, Weissenborn $\mathrm{K}$, Prange $\mathrm{H}$, Schneider D, Weimar C, Wartenberg K, et al. Recombinant human erythropoietin in the treatment of acute ischemic stroke. Stroke. 2009 Dec;40(12):e647-56.

27. Center for Drug Evaluation and Research (CDER). Guidance for industry: estimating the maximum safe starting dose in initial clinical trials for therapeutics in adult healthy volunteers [Internet]. Washington, D.C.: Department of Health and Human Services; Food and Drug Administration (FDA); 2005 [cited $2020 \mathrm{Apr}$ 21]. 27 p. Available at: https://www.fda.gov/ media/72309/download

28. Sosa Testé I, Megana Tamos Y, Rodríguez Cruz Y, Muñoz Cernada A, Cruz Rodríguez J, Subirós Martínez N, et al. Dose effect evaluation and therapeutic window of the Neuro-EPO nasal application for the treatment of the focal ischemia model in the Mongolian gerbil. Sci World J. 2012;2012:607498. DOI: 10.1100/2012/607498

29. Reglamento para la vigilancia de productos farmacéuticos de uso humano durante la comercialización. Resolución 69/2019 [Internet] Havana: Center for State Control of Medicines, Equipment and Medical Devices (CECMED) 2019 [cited 2020 May 18]. 49 p. Available at: https://www.cecmed.cu/sites/default/files/ adjuntos/Reglamentacion/Res.No_.69.2019\%20 Peq.pdf. Spanish.

30. De Cos MA, Flórez J. Reacciones Adversas de los Medicamentos. In: Flórez J, editor.
Farmacología Humana. 3rd ed. Barcelona: Masson; 1998. p. 155-64. Spanish.

31. Theuse oftheWHO-UMC systemforstandardized case causality assessment [Internet]. Uppsala (SW): The Uppsala Monitoring Center; [date unknown; cited 2020 Apr 21]. 2 p. Available at: http://www.who.int/medicines/areas/quality _safety/safety_efficacy/WHOcausality_assess ment.pdf

32. Declaración de Helsinki de La Asociación Médica Mundial. Principios éticos para las investigaciones médicas en seres humanos. Fortaleza: 64 ${ }^{\mathrm{a}}$ Asamblea General [Internet]. Pamplona (SP): Universidad de Navarra, Centro de Documentación de Bioética; 2013 [updated 2013 Oct; cited 2019 Jul 23]. 7 p. Available at: http://www.redsamid.net/archivos/201606/2013 -declaracion-helsinki-brasil.pdf?1. Spanish.

33. Wooten GF, Currie LJ, Bovbjerg VE, Lee JK, Patrie J. Are men at greater risk for Parkinson's disease than women? J Neurol Neurosurg Psychiatry [Internet]. 2004 Apr [cited 2020 Apr 21];75(4):637-9. Available at: https://doi .org/10.1136/jnnp.2003.020982

34. Pringsheim T, Jette N, Frolkis A, Steeves TDL. The prevalence of Parkinson's disease: a systematic review and meta-analysis. Move Disord [Internet]. 2014 [cited 2020 21];29(13):1583-90. Available at: https://doi .org/10.1002/mds. 25945

35. Lombardero M, Kovacs K, Scheithauer BW. Erythropoietin: a hormone with multiple functions. Pathobiology [Internet]. 2011 [cited 2020 Mar 18];78(1):41-53. Available at: https:// doi.org/10.1159/000322975

36. Ribatti D, Vacca A, Roccaro AM, Crivellato E, Presta M. Erythropoietin as an angiogenic factor. Eur J Clin Invest. 2003 Oct;33(10):891-6.

\section{THE AUTHORS}

Marité García-Llano, physician with dual specialties in family medicine and neurology, and a master's degree in medical emergencies. Head of the Neurology Department, Abel Santamaría Cuadrado Provincial Clinical-Surgical Hospital, Pinar del Río, Cuba. https://orcid.org/0000 $-0002-4896-8948$

Ivonne Pedroso-Ibáñez, physician with dual specialties in family medicine and neurology, and a master's degree in clinical neuroscience. Head of the Movement Disorders Clinic, International Neurological Restoration Center (CIREN), Havana, Cuba. Associate researcher and assistant professor, Cuban Neurosciences Center (CNEURO). https://orcid.org/0000-0001-6983 $-9398$

Lilia Morales-Chacón, physician specializing in neurophysiology, with dual doctorates in physiology and medical sciences. Senior researcher at CIREN and full professor at the Medical University of Havana, Cuba. Deputy director, CIREN, Havana, Cuba. https://orcid.org/0000-0003 $-0205-0733$

Teresita Rodríguez-Obaya, physician specializing in cellular biology and histology with a doctorate in biological sciences. NeuroEPO product manager, associate researcher, Molecular Immunology Center (CIM), and full professor, Medical University of Havana, Cuba. https://orcid.org/0000 -0002-2918-4267 
Leslie Pérez-Ruiz, pharmacist with master's degrees in pharmacology and health economics. Assistant researcher and assistant professor, Molecular Immunology Center (CIM), Havana, Cuba. https://orcid.org/0000-0001 $-8492-3774$

Iliana Sosa-Testé, veterinarian with a doctorate in veterinary sciences. Head of Toxicology and Animal Experimentation Department, senior researcher and professor at the National Laboratory Animal Production Center (CENPALAB), Havana, Cuba. https://orcid.org/0000-0001 $-6588-5397$
Daniel Amaro-González, chemical engineer with a doctorate in the field. Head of the Department of Vaccine Development, full professor and associate researcher, CIM, Havana, Cuba. https://orcid.org/0000-0001 $-5729-2743$

María Luisa Bringas-Vega (Corresponding author: maria.bringas@neuroinformatics-collaboratory.org), psychologist with a doctorate in psychophysiology. Coordinator of the Cuba-China Joint Lab for Neurotechnology. Full professor of neuropsychology in the master's degree pro- gram in cognitive neurosciences, CNEURO, Havana, Cuba. https://orcid.org/0000-0003 $-2507-1959$

Submitted: March 17, 2020

Approval date: December 5, 2020

Disclosures: Teresita Rodríguez-Obaya, Leslie Pérez-Ruiz and Daniel Amaro-González work at the Molecular Immunology Center (CIM), the developer of EPOCIM and NeuroEPO. 